\title{
Speed Control of a Single Taipei Mass Rapid Transit System Train by Using a Single Input Fuzzy Logic Controller
}

\author{
Hari Maghfiroh $^{1}$, Oyas Wahyunggoro ${ }^{1}$, Adha Imam Cahyadi ${ }^{1}$, Kuo Lung Lian ${ }^{2}$, Bwo Ren Ke \\ ${ }^{1}$ Dept. of Electrical Engineering and Information Technology, Universitas Gadjah Mada, Yogyakarta, Indonesia \\ ${ }^{2}$ Dept. of Electrical Engineering, National Taiwan University of Science and Technology, Taipei, Taiwan \\ ${ }^{3}$ Dept. of Electrical Engineering, National Penghu University of Science and Technology, Penghu, Taiwan
}

\section{Article Info}

Article history:

Received Jul 13, 2015

Revised Dec 19, 2015

Accepted Jan 12, 2016

\section{Keyword:}

Fuzzy logic controller

Mass rapid transit

Railway

Single input fuzzy

\begin{abstract}
The purpose of this study was to design a speed controller for mass rapid transit (MRT) train by using a single input fuzzy logic controller (SIFLC). A complete train model, which was designed according to the design of a Taipei MRT train, was used for analyzing both mechanical and electrical parts. The SIFLC was used for improving a fuzzy logic controller (FLC) by reducing its number of control rules. The results indicated that the SIFLC exhibited more favorable performance than the FLC did and a substantial reduction in the number of fuzzy rules and processing time. Therefore, tuning the SIFLC was easier compared with tuning the FLC; furthermore, the simulation time of the SIFLC was shorter than that of the FLC, exhibiting reductions of up to $17.3 \%$ in a constant track (track without gradient and curvature) and up to $12.27 \%$ in a variable track (track with gradient and curvature).
\end{abstract}

Copyright (c) 2016 Institute of Advanced Engineering and Science. All rights reserved.

\section{Corresponding Author:}

H. Maghfiroh,

Departement of Electrical Engineering and Information Technology,

Universitas Gadjah Mada,

Yogyakarta, Indonesia.

Email: hari.maghfiroh@gmail.com

\section{INTRODUCTION}

Mass rapid transit (MRT) systems play a crucial role in public transportation because of their high efficiency and ridership, especially in high population density areas such as metropolitan areas. The Taipei Rapid Transit System (TRTS), also called Taipei Metro, was established by the Department of Rapid Transit Systems and operated by Taipei Rapid Transit Corporation. The TRTS comprises 109 stations and 11 lines, with a total of $121.3 \mathrm{~km}$ of revenue track, and it transported, on average, more than 1.96 million passengers per day in May 2015 [1].

Automatic train operation (ATO) is an integrated automation train control system which has a direct impact in the development of train operation system. Therefore, the study of ATO has attraced significant attention in the recent decades. Chiu [2] proposed a Taipei MRT model that using a proportional-integralderivative (PID) controller method. The PID gains are usually determined through trial and error, and this method may not return optimal gains. A fuzzy logic controller (FLC) is a widely used device for controlling train speed. Yasunobu et al. [3] designed a fuzzy ATO controller that can control a train automatically. Chang et al. [4] also applied fuzzy logic rules to an ATO controller to provide multiobjective control for satisfying various railway operational requirements. Both of these fuzzy ATO controllers can perform effectively and are superior to PID controllers.

Chang and $\mathrm{Xu}$ [5] used differential evolution (DE) algorithm based tuning to implement a fuzzy ATO. DE is used for optimizing fuzzy membership functions. Tao et al. [6] proposed a multi mode intellifent control using Bang-bang-Fuzzy-PI switching control for speed control of high speed railway. The purpose of 
mixed controllers is that the bang-bang control is used when the error is too large, then to get the smaller error, the fuzzy control is used. When the error is vey small, PID controller is used. Ke et al. [7] proposed a fuzzy-PID gain scheduler for tracking the speed of MRT trains, and the proposed scheduler exhibited high performance under acceleration restrictions. However, they used complex and time consuming three dimensional windows for fuzzy rules. FLCs require a long computational time that is proportional to the number of fuzzy rules. The current study proposes a simple single input fuzzy logic controller (SIFLC) for replacing FLCs in speed control of mass rapid transit (MRT) train.

The SIFLC essentially has the same concept as that of FLCs; however, it uses just one input. Therefore, it offers a considerable reduction in fuzzy rules. Choi et al. [8] proposed the SIFLC and proved that it operates effectively in regulation and tracking problems. Londhe et al. [9] used an SIFLC to perform spatial control of an advanced heavy water reactor, and their results showed that the SIFLC had superior performance and a shorter computation time compared with a conventional FLC. Ishaque et al. [10] used an SIFLC to control an unmanned underwater vehicle; they concluded that the SIFLC exhibited higher tenability and a shorter computation time compared with an FLC. Therefore, the SIFLC can be implemented in slow processors at a low cost. Chiang et al. [11] used an SIFLC as a regulation control for intelligent vehicles because of its simplicity compared with conventional FLCs.

The rest of this paper is organized as follows. Section II presents the MRT model. Section III presents the formulation of the proposed SIFLC Controller. The results and case study analysis are described in Section IV. Finally, the conclusion is provided in Section V.

\section{MASS RAPID TRANSIT MODEL}

A train model of the Bannan Line of the Taipei MRT was constructed using MATLAB-Simulink. The modeled train is an electrical multiple unit (EMU) that comprises two motor cars and a trailer car. For simulating speed control, the train propulsion system and track profiles were modeled. Because the train derives power from third rails, a third rail model was also included. Data on the Taipei MRT system regarding the train, track, and third rail were used in the model.

The propulsion system of the Bannan Line of the Taipei MRT comprises an AC induction motor controlled by a variable-voltage variable-frequency (VVVF) controller by means of V/f technique[2]. The three phase voltage are measured and compared with the reference value of voltage required and then the required frequency of pulse are generated by the PWM generator so as to maintain a constant torque even at lower speed [12]. The Taipei MRT uses three switching methods according to the train speed; SPWM is used at $0-22 \mathrm{~km} / \mathrm{h}$, a quasi-six-step method is used at $22-42 \mathrm{~km} / \mathrm{h}$, and a six-step method is used at $42-80 \mathrm{~km} / \mathrm{h}$ [13].

Taipei MRT trains derive power from a traction substation (TSS) through a third rail with a $750 \mathrm{~V}$ dc system. This study examined the speed control of a single train that operates between two TSSs. Figure 1 shows the current flow through the train and its resistances.

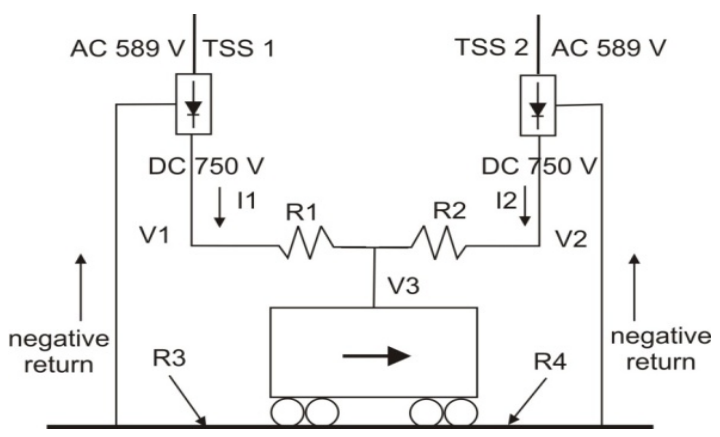

Figure 1. Current flow from two TSS through a train

The electrical resistances can be formulated as follows:

$$
\begin{aligned}
& R_{1}=\rho_{1} \int v d t \\
& R_{2}=\rho_{1} L-R_{1}
\end{aligned}
$$




$$
\begin{aligned}
& R_{3}=\rho_{2} \int v d t \\
& R_{4}=\rho_{2} L-R_{3}
\end{aligned}
$$

where $R_{1}$ is the third rail resistance from TSS $1(\Omega), R_{2}$ is the third rail resistance from TSS $2(\Omega), R_{3}$ is the running rail resistance connected to TSS $1(\Omega), R_{4}$ is the running rail resistance connected to TSS $2(\Omega), \rho_{1}$ is the third rail resistance per kilometer $(\Omega / \mathrm{km}), \rho_{2}$ is the running rail resistance per kilometer $(\Omega / \mathrm{km}), v$ is the train speed $(\mathrm{km} / \mathrm{h})$, and $L$ is the distance between two TSSs $(\mathrm{km})$.

There are four types of force resistance, which are starting resistance $\left(R_{S}, \mathrm{kN}\right)$, running resistance $\left(R_{R}, \mathrm{kN}\right)$, gradient resistance $\left(R_{G}, \mathrm{kN}\right)$, and curve resistance $\left(R_{C}, \mathrm{kN}\right)$. Running resistance is adopted from the Davis equation as (5):

$$
R_{R}=A+B v+C v^{2}
$$

where $A$ is the coefficient in N,B is the coefficient in Ns/m, and $C$ is the coefficient in $\mathrm{Ns}^{2} / \mathrm{m}^{2}$. Furthermore, $R_{G}$ occurs because of the track gradient, and its value is related to the train mass as expressed in (6):

$$
R_{G}=M g \sin \theta
$$

where $M$ is the mass of the train (ton), $g$ is gravitational acceleration $\left(\mathrm{m} / \mathrm{s}^{2}\right)$, and $\theta$ is the angle of gradient. Curve resistance, as expressed in (7), is caused by the effect of track curve [14].

$$
R_{c}=0.01\left(\frac{k}{r}\right)
$$

Here, $k$ is a dimensionless parameter (depending on the train design, and varies from 500 to 1200 with 800 as the average) and $r$ is the curve radius ( $\mathrm{m})$ on a horizontal plane. As expressed in (8), the total resistance $(R)$ is the sum of all of the aforementioned resistances.

$$
R=R_{S}+R_{R}+R_{G}+R_{C}
$$

Therefore, the motion equation becomes

$$
F=M a-R
$$

where $F$ is traction force $(\mathrm{kN})$ and $a$ is the train acceleration $\left(\mathrm{m} / \mathrm{s}^{2}\right)$.

\section{CONTROLLER DESIGN}

\subsection{Fuzzy Logic Controller}

Zadeh introduced the fuzzy logic system (FLS) in 1965, and Mamdani developed the first fuzzy control model in 1981 [15]. In a control system, the FLS is called as Fuzzy Logic Controller (FLC). An FLC requires simpler mathematics and offers a higher degree of freedom in tuning its control parameters compared with other nonlinear controllers [10]. An FLC comprises four components, which are fuzzification, a rule base, an inference mechanism, and deffuzification. Figure 2 shows the components of a fuzzy controller with two inputs (error $(e)$ and change of error $(\dot{e}))$ and one output (controller signal $(u)$ ).

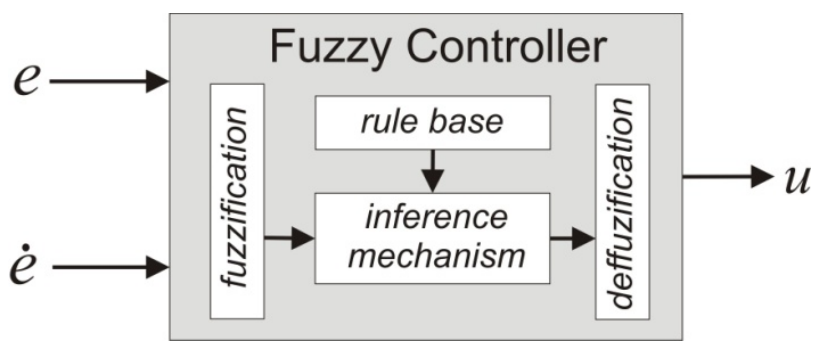

Figure 2. FLC structure 


\subsection{Single Input Fuzzy Logic Controller}

The main inputs of an FLC are error and change of error, regardless of the complexity of plants. A two dimensional (2D) rule table is then constructed on a phase plane (e, $\dot{e})$. The output of the FLC is applied to the plant as the controller signal $u$. Most rule tables of FLCs have a skew-symmetry property [8]. In this structure, the same output memberships are arranged in a diagonal direction, constituting the main characteristic of the structure (Table 1). In this case, five memberships are used, namely positive big (PB), positive small (PS), zero (Z), negative small (NS), and negative big (NB). The magnitude of each point on a particular diagonal line is proportional to the distance from its main diagonal line. This property enables using signed distance, which is the distance from the main diagonal line to an actual state [8]. The derived signed distance is then used as the fuzzy input. The input of the FLC is thus only one variable. Therefore, the rule base is considerably reduced compared with that of conventional FLCs.

As shown in Table 1, the boundaries of $e$ and $\dot{e}$ in the same control output are shaped like a staircase. If the quantization level of the independent variables becomes infinitesimal, then the boundaries become straight lines (Figure 3). The absolute magnitude of the control input is proportional to the signed distance $(d)$ from the main diagonal. To determine $d$, assume $B\left(e_{0}, \dot{e}_{0}\right)$ is an intersection point of the main diagonal line and the line perpendicular to it from a known operating point $A\left(e_{1}, \dot{e}_{1}\right)$ (Figure 4).

Table 1. FLC rule table

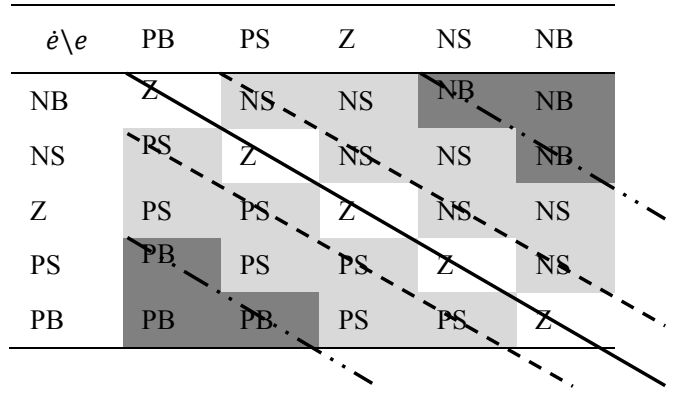

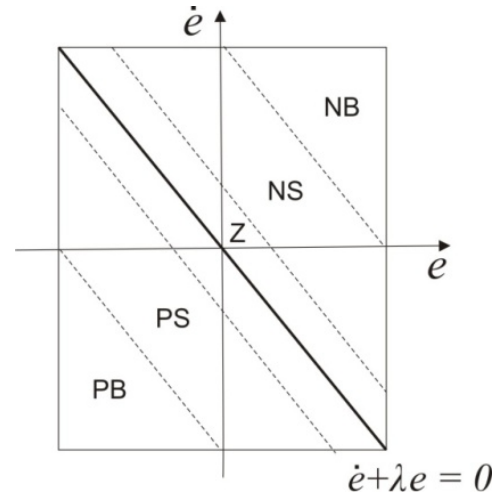

Figure 3. Rule Table with Infinitesimal Quantization Levels

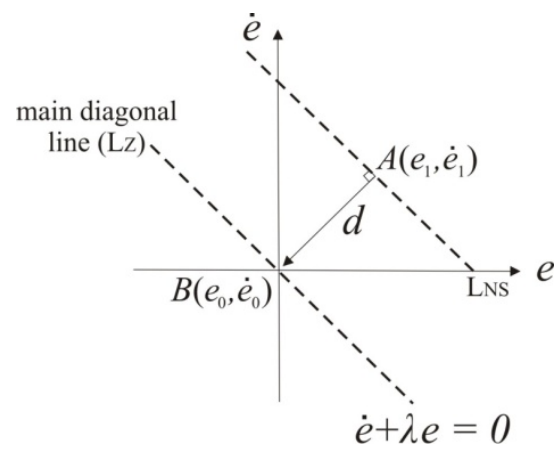

Figure 4. Signed Distance

The main diagonal is a switching line or sliding surface that can be represented as follows:

$$
s: \dot{e}+\lambda e=0
$$

where $\lambda$ is the slope of the main diagonal line $\mathrm{L}_{Z}$ (Figure 3). The distance between points $\mathrm{A}$ and $\mathrm{B}$ can be calculated as follows:

$$
d_{1}=\sqrt{\left(e_{0}-e_{1}\right)^{2}+\left(\dot{e}_{0}-\dot{e}_{1}\right)^{2}}=\frac{\left|\dot{e}_{1}+\lambda e_{1}\right|}{\sqrt{1+\lambda^{2}}}
$$

In general, this equation can be rewritten as follows: 


$$
d=\frac{|\dot{e}+\lambda e|}{\sqrt{1+\lambda^{2}}}
$$

For any arbitrary point, $A\left(e_{1}, \dot{e}_{1}\right)$, the signed distance $\left(d_{s}\right)$ is defined as follows:

$$
d_{s}=\operatorname{sgn}(s) \frac{|\dot{e}+\lambda e|}{\sqrt{1+\lambda^{2}}}=\frac{\dot{e}+\lambda e}{\sqrt{1+\lambda^{2}}}=\frac{s}{\sqrt{1+\lambda^{2}}}
$$

where

$$
\operatorname{sgn}(s)=\left\{\begin{array}{r}
-1, s<0 \\
1, s>0
\end{array}\right.
$$

Because the sign of the control input is negative when $s>0$ and positive when $s<0$ and because its magnitude is proportional to the distance from $s=0$, then [9]

$$
u \propto-d_{s}
$$

Since the control action can be determined by only $d_{s}$, it is appropriate to call the controller a SIFLC. The 2D rule table can be converted into a one dimensional rule table (Table 2), where $\mathrm{L}_{\mathrm{NB}}$ is the signed distance of NB to the main diagonal $\left(\mathrm{L}_{\mathrm{Z}}\right)$ (refer to Figure 3). Therefore, the number of rules is considerably reduced compared with that of the FLC. Furthermore, the rules can be added or modified to achieve fine control.

Table 2. Rule Table of SIFLC

\begin{tabular}{llllll}
\hline$d_{s}$ & $\mathrm{~L}_{\mathrm{NB}}$ & $\mathrm{L}_{\mathrm{NS}}$ & $\mathrm{L}_{\mathrm{Z}}$ & $\mathrm{L}_{\mathrm{PS}}$ & $\mathrm{L}_{\mathrm{PB}}$ \\
\hline$u$ & $\mathrm{~PB}$ & $\mathrm{PS}$ & $\mathrm{Z}$ & $\mathrm{NS}$ & $\mathrm{NB}$ \\
\hline
\end{tabular}

Depending on the fuzzy inference and defuzzification method used, the FLC provides either a linear or nonlinear interpolation. The SIFLC uses linear interpolation; therefore, the control signal becomes

$$
u=-K_{d} d_{s}
$$

where $K_{d}>0$ is a constant.

Figure 5 shows the SIFLC structure. When the signed distance method is used, the two inputs $(e$ and $\dot{e})$ become one input $\left(d_{S}\right)$. The difference between the FLC and SIFLC can be clearly observed by comparing Figures 2 and 5. The SIFLC has numerous advantages in comparison with FLCs [16]: It requires only one input variable (i.e., signed distance), regardless of the complexity of the plants. The number of tuning parameters is considerably decreased. Therefore, tuning the rules, membership functions, and scaling factors is much easier in the SIFLC than in an FLC. It is equivalent to a sliding mode control (SMC) with a boundary layer. This fact evidences the close-loop stability of the SIFLC.

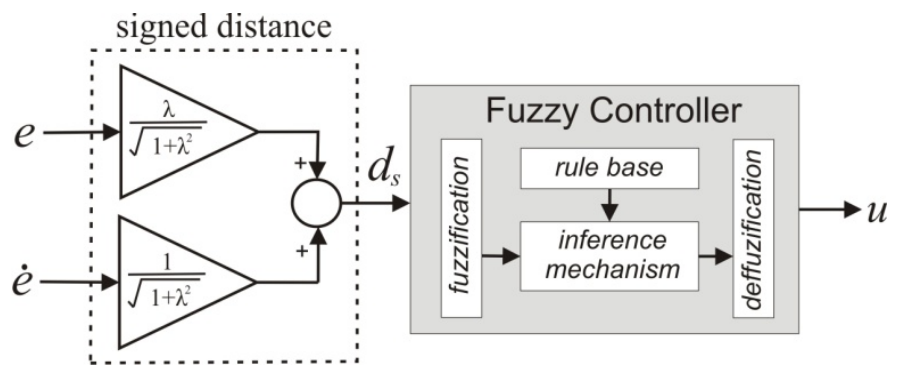

Figure 5. SIFLC Structure

\section{SIMULATION RESULT AND DISCUSSION}

The distance between two stations was $1276 \mathrm{~m}$, and the speed limit and speed reference were 80 $\mathrm{km} / \mathrm{h}$. Acceleration and jerk restrictions were set to within $1 \mathrm{~m} / \mathrm{s}^{2}$ and $\pm 1 \mathrm{~m} / \mathrm{s}^{3}$, respectively, in accordance with the Taipei MRT regulations. In this case, the gradient and curve resistances were considered as shown in 
Table 3 and 4, respectively. Constant track and variable track were used for validating the performance of the proposed controller. Constant track refers to track without gradient and curvature, whereas variable track refers to track with gradient and curvature.

The simulation was performed in the MATLAB-Simulink environment. Triangular membership functions, Mamdani inference, and center of gravity defuzzification were used in both the FLC and SIFLC. Five membership functions were used: NB, NS, Z, PS, and PB.

Table 3. Track Gradient

\begin{tabular}{ccc}
\hline Start Point (m) & End Point (m) & Gradient (\%) \\
\hline 0 & 160 & 0 \\
160 & 561 & -2.11 \\
561 & 928 & 2.43 \\
928 & 1143 & 0.3 \\
1143 & 1276 & 0 \\
\hline
\end{tabular}

Table 4. Track Curvature

\begin{tabular}{ccc}
\hline Start Point (m) & End Point (m) & Radius (m) \\
\hline 0 & 201 & 0 \\
201 & 287 & 280 \\
287 & 428 & 0 \\
428 & 514 & 280 \\
514 & 870 & 0 \\
870 & 999 & 1000 \\
999 & 1276 & 0 \\
\hline
\end{tabular}

\subsection{Constant Track}

Figure 6 illustrates the speed versus time curve, indicating that, compared with the FLC, the SIFLC had a faster response at the same starting time and braking point. The SIFLC exhibited a shorter settling time and simulation time. In this case, the SIFLC was faster than the FLC by $17.3 \%$. This proves that the SIFLC has a shorter computation time than the FLC does, because it contains fewer fuzzy rules. Both the SIFLC and FLC did not show overshoot or undershoot.

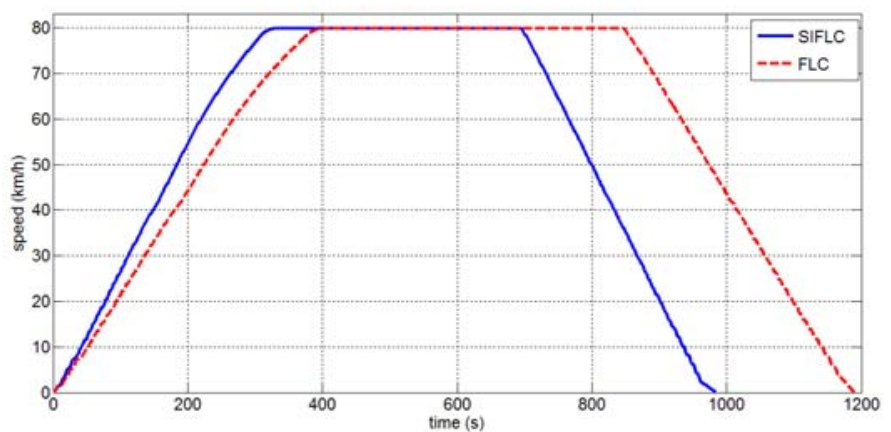

Figure 6. Speed vs. Time for Constant Track 


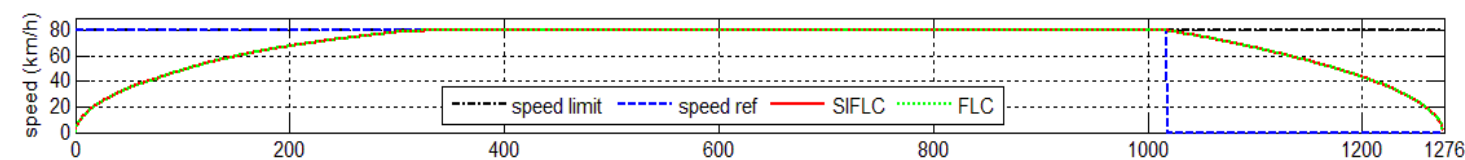

(a)

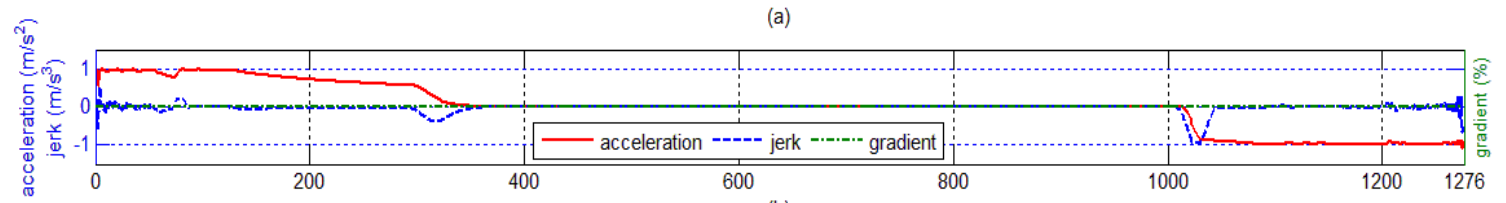

(b)

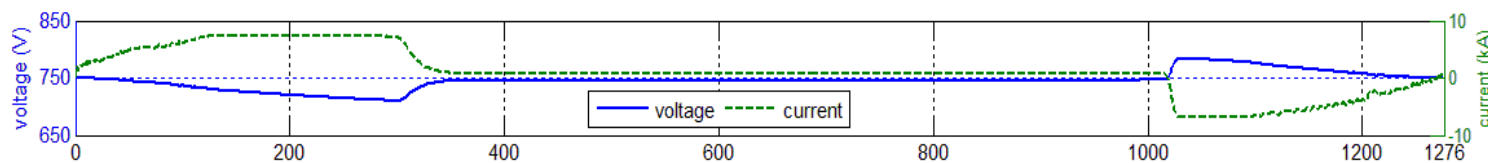

(c)

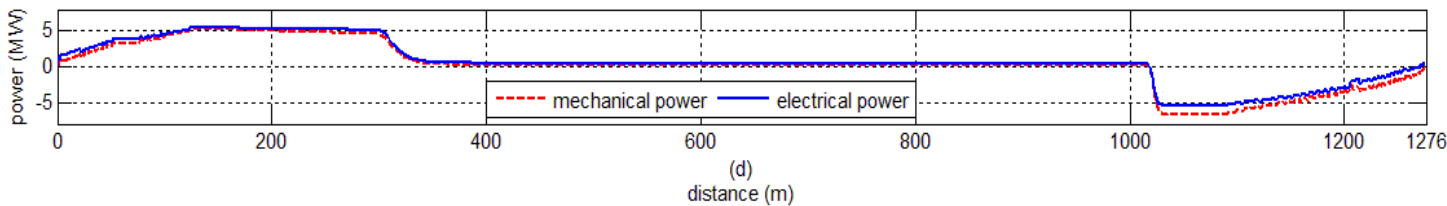

Figure 7. Constant Track: (a) Speed vs. distance (b) Acceleration, jerk, and gradient vs. distance (c) Voltage and current vs. distance (d) Power vs. distance

Figure 7 shows a speed versus distance curve as well as an electrical curve (voltage, current, and power) which depicted the speed response, acceleration and jerk restrictions, regenerative braking, and also model's efficiency. Figure 7(a) depicts the speed curve, indicating that the speed response was consistent with the speed command and the train was stop at target distance. The acceleration curve ascended when the speed command was increased and it descended when the speed command was decreased. The jerk curve, which is the derivative of the acceleration, exhibited the same phenomenon. The highest acceleration occured when the train started to run, while negative value of acceleration means that braking was activated. Both the acceleration and jerk were still below the limit of $\pm 1 \mathrm{~m} / \mathrm{s}^{2}$ for acceleration and $\pm 1 \mathrm{~m} / \mathrm{s}^{3}$ for jerk, Figure 7(b). The gradient in this case was zero. Figure 7(c) shows the voltage and current curves of contact shoes. The voltage and current were inversely proportional; that is, when the voltage was at a minimum, current was at a maximum and vice versa. However, the current was proportional to power. When the train consumed energy, the power consumption curve increased. When the train obtained energy from the third rail, its energy decreased (represented by the voltage of the contact shoes). When the train stopped, the voltage of the contact shoes was equal to that of the third rail (i.e., $750 \mathrm{~V} \mathrm{dc}$ ). A voltage value that was lower than $750 \mathrm{~V}$ indicated that the train absorbed the energy. On the other hand, a voltage value higher than $750 \mathrm{~V}$ indicated that the train released energy through regenerative braking. Because of the acceleration and jerk limitation, the maximum voltage was lower than $900 \mathrm{~V}$, indicating that it did not exceed the limit of the third rail voltage, which was $900 \mathrm{~V}$. Figure 7(d) depicts the power curve; both the electrical and mechanical curves are also shown in this figure. These two curves are nearly the same, indicating that the system efficiency was favorable.

\subsection{Variable Track}

After the proposed controller was proved to operate effectively in the constant track case, this study tested its performance in a variable track case. Figure 8 shows the speed versus time curve for the variable track, indicating that the SIFLC had a faster response compared with the FLC. The SIFLC exhibited a shorter settling time and simulation time. In this case, the simulation time of both the SIFLC and FLC increased compared with the case of the constant track because of the gradient and curve effects. In this case, the SIFLC was still faster than the FLC by $12.27 \%$. This proved that the SIFLC has a shorter computation time. The track gradient caused a little over-shoot and under-shoot in the response speed. However, this value was low (lower than $0.5 \mathrm{~km} / \mathrm{h}$ ) and, thus, can be tolerated. 


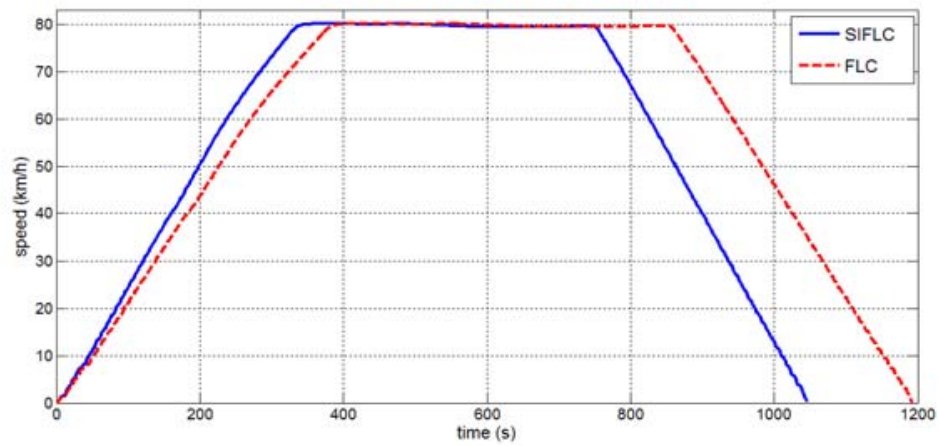

Figure 8. Speed vs. Time for Variable Track

Figure 9(a) shows the speed curve versus distance. Although there were some gradient changes, the speed response was consistent with the speed command. Figure 9(b) shows acceleration, jerk, and gradient curves, indicating that the acceleration curve was below the limit of $\pm 1 \mathrm{~m} / \mathrm{s}^{2}$ and the jerk was in the limit of \pm $1 \mathrm{~m} / \mathrm{s}^{3}$, despite the existence of gradient changes. Negative gradients or downhill tracks consume less energy than zero gradients do because the regenerative braking was activated to maintain the speed at the desired level, as shown at the 400-m distance. However, positive gradients or uphill tracks consume more power compared with zero and negative gradients, for example, Figure 9(d) clearly depicts this effect at the 800-m distance.
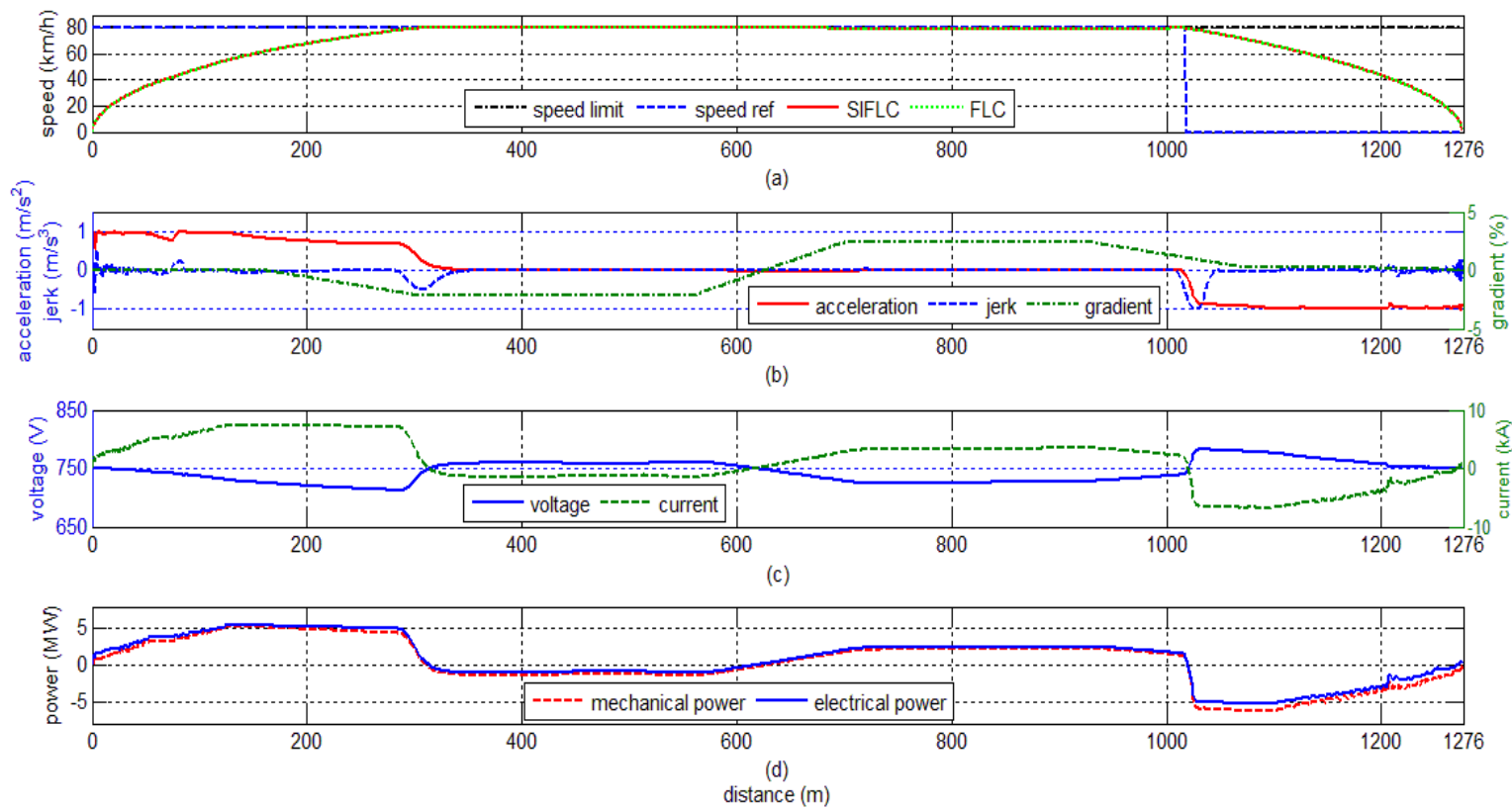

Figure 9. Variable Track: (a) Speed vs. distance (b) Acceleration, jerk, and gradient vs. distance (c) Voltage and current vs. distance (d) Power vs. distance

\section{CONCLUSION}

This study involved modeling and controlling Taipei MRT trains. Case studies with different schemes were performed. The results indicated that the SIFLC exhibited more favorable performance than the FLC did and a substantial reduction in the number of fuzzy rules. Therefore, tuning the SIFLC was easier compared with tuning the FLC; furthermore, the simulation time of the SIFLC was shorter than that of the FLC. The SIFLC adopts the SMC method; therefore, its stability is guaranteed. It can be concluded that SIFLC can be used to replace FLC in speed control of mass rapid transit (MRT) train. 


\section{REFERENCES}

[1] May 2015. [Online]. Available: http://web.metro.taipei/RidershipCounts/E/10405e.htm.

[2] H.W. Chiu, Master Thesis: Simulation and Analysis of Train Performance Based on Actual MRT Operation Characteristics, Taipei: NTUST, 2013.

[3] S. Yasunobu, Miyamoto S. and H. Ihara, "A fuzzy control for train automatic stop control," in Trans. Soc. Instrum. Control Engineering, E-2(1), pp. 1-9, 2002.

[4] C. Chang, D. Xu and H. Quek, "Pareto-optimal set based multiobjective tuning of fuzzy automatic train operation for mass transit system," IEE Proc.Electrical Power Application, vol. 146, no. 5, pp. 577-583, September 1999.

[5] C. Chang and D. Xu, "Differential evolution based tuning of fuzzy automatic train operation for mas rapid transit system," IEE Proceeding Electrical Power Application, vol. 147, no. 3, pp. 206-212, May 2000.

[6] H. Tao, N. Hongxia, and F. Duowang, "Speed Control of High-speed Railway on Multi-mode Intelligent Control and Feature Recognition," in TELKOMNIKA Indonesian Journal of Electrical Engineering, vol.10, no. 8, pp. 20692074, December 2012.

[7] B.R. Ke, C.L. Lin and C.W. Lai, "Optimization of train speed trajectory and control of mass rapid transit systems," Control Engineering Practice, vol. 19, pp. 675-687, April 2011.

[8] B.J. Choi, S.W. Kwak and B.K. Kim, "Design of a single-input fuzzy logic controller and its properties," Fuzzy Sets and Systems ELSEVIER, vol. 106, pp. 299-308, 1999.

[9] P. Londhe, B. Patre and A. Tiwari, "Design of Single-Input Fuzzy Logic Controller for Spatial Control of Advanced Heavy Water Reactor," IEEE Transaction on Nuclear Science, vol. 61, no. 2, pp. 901-911, April 2014.

[10] K. Ishaque, S. Abdullah, S. Ayob and Z. Salam, "Single Input Fuzzy Logic Controller for Unmanned Underwater Vehicle," J Intell Robot Syst, pp. 87-100, February 2010.

[11] H.H. Chiang, S.J. Wu, J.W. Perng, B.F. Wu, and T.T. Lee, "The Human-in-the-Loop Design Approch to the Longitudinal Automation System for an Intelligent Vehicle," IEEE Transaction on Systems, Man, and Cybernetics, vol. 40, no. 4, pp. 708-720, Jul. 2010.

[12] C. Nagamani, R. Somanathan, U.C. Kumar, " Design and Analysis of Drive System with Slip Ring Induction Motor for Electric Traction in India," in International Journal of Power Electronics and Drive System (IJPEDS), vol. 5, pp. 374-382, February 2015.

[13] Y.T. Hsiao and K.C. Lin, "Measurement and Characterization of Harmonics on the Taipei MRT DC System," IEEE Transactions on Industry Applications, vol. 40, no. 6, pp. 1700-1704, November/December 2004.

[14] B. Rochard and F. Schmid, "A review of methods to measure and calculate train resistance," Journal of Rail and Rapid Transit, pp. 185-199, 2000.

[15] S. Pravadalioglu, "Single-chip fuzzy logic controller design and an application on a permanent magnet dc motor," Engineering Application on Artificial Intelligence, pp. 881-890, May 2005.

[16] B.J. Choi, S.W. Kwak and B.K. Kim, "Design and Stability Analysis of Single-Input Fuzzy Logic Controller," IEEE Transaction on Systems, Man, and Cybernetics, vol. 30, no. 2, pp. 303-309, April 2000. 